\title{
DISCUSSION
}

\section{The failure of Carsington Dam}

\author{
A. W. SKEMPTON and P. R. VAUGHAN (1993). Géotechnique 43, No. 1, 151-173
}

\section{Investigation of the failure of Carsington Dam}

\author{
G. ROCKE (1993). Géotechnique 43, No. 1, 175-180
}

\section{A. D. M. Penman, Geotechnical Engineering Con- sultant}

I began the investigation at Carsington. I was engaged by the Contractor's Insurers on the day after the failure, and was the first external expert on the site. The workforce had been stood down and we had the site to ourselves for several days. With the help of Brian Rostron, the Contractor's geotechnical engineer, we began the trial pit at ch. $620 \mathrm{~m}$ and soon exposed the slip surface at the toe. I engaged Soil Mechanics Ltd, and the first hole I asked them to make was intended to obtain a sample of the yellow clay from under the greatest height of fill, just upstream of the boot. I intended to use the foundation drainage layer as a marker, stabilize it and drill carefully through to obtain an undisturbed sample of the yellow clay. But the borehole (SM 1 in Fig. 25) went into the grey mudstone without finding the bottom drainage layer: the layer had moved upstream so far as to be missed. This proved that the slip surface passed below all the fill of the upstream shoulder. We knew where it was at the toe and, very clearly, at the top, so this showed that it followed the line of the worst surface found by Rofe Kennard and Lapworth in their analysis made six months beforehand.

During the early investigation a large sample of the shear surface through the yellow clay was taken, which was preserved by drying and varnishing. It showed considerable slickensiding in the direction of shear. Werc the undulations across the shear zone taken into account in the subsequent investigations?

Almost since Telford's time, the traditional design for this type of small dam has been with $1: 3$ upstream and $1: 2$ or $2 \frac{1}{2}$ downstream slopes, with a central puddled clay core taken down into the foundation as a cut-off. The downstream shoulder of Carsington followed this tradition and it has been completely stable. The upstream shoulder was handicapped by the mysterious boot. It would seem that the dam designers were very concerned to maximize the length of the seepage path under the dam but had no eye for slip surfaces.

We have enjoyed the facility of computerized limit state stability analysis for 35 years. There are at least 17 commercially available programmes which all require values of $c^{\prime}, \phi^{\prime}$ and $r_{\mathrm{u}}$ or other data on pore water pressure. The accurate prediction of pore pressures is extremely difficult and it is always essential to make field measurements to check that the design assumptions were not dangerously incorrect.

A value of $c^{\prime}$ comes from assuming a linear relation between shear strength and normal load. It is the strength of the soil at zcro normal load.

Professor Jenkins at the Building Research Station more than 60 years ago built a counterbalanced ring shear apparatus to measure shear strength at zero normal load, but had no means of measuring pore water suction, so he could not get $c^{\prime}$. We rely on some interaction between clay particles to produce some amount of true $c^{\prime}$ to prevent dispersion in non-dispersive soils, but it is a tenuous value to rely on as a contribution to strength in stability analysis.

The failure envelope of all particulate materials is curved and it is reasonable to assume $c^{\prime}=0$ in design. Fig. 26 is Fig. 19(c) with the peak strength values from Fig. 18 added. There is no evidence at low normal stresses that the failure envelope docs not curve down to a realistically small value of $\tau$ at the zero value of $\sigma_{\mathrm{n}}^{\prime}$. The Rofe Kennard and Lapworth analysis used $c^{\prime}=0$ and gave warning that the factor of safety might fall to one if the dam were raised to full height without some modification to the design. Fig. 27 shows the results obtained from that limit state analysis.

For the past 25 years I have felt that simply applying a factor of safety against the unacceptable concept of complete collapse contemplated by limit state analysis was unsatisfactory and that 


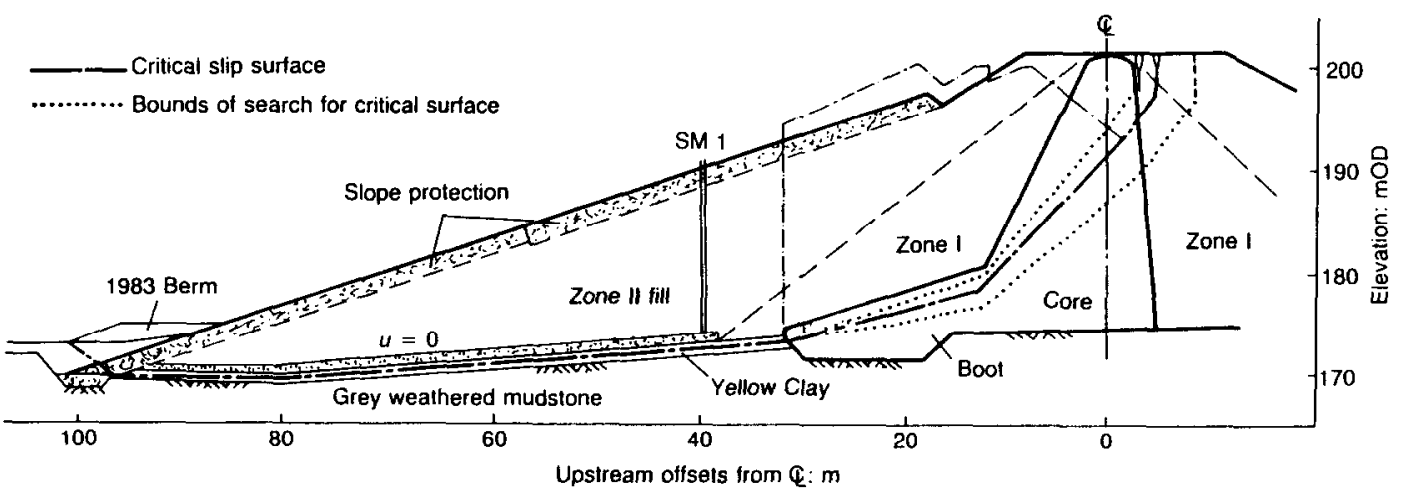

Fig. 25

design should be for acceptable movements and strains. With this in mind, I have measured the movements of dams by very accurate field measurements whenever I have had the opportunity (Penman, 1986).

Potts, Dounias \& Vaughan (1990) and Chen, Morgenstern \& Chan (1992) present finite element methods for analysing movements and strains and for allowing for strain-softening materials and considerations of progressive failure. These methods of analysis may be the best things to have come out of the Carsington investigation.

We must always be grateful for the opportunity to analyse failure--without failure we know less about the actual mechanisms of failure and $I$ am sure that these new methods will be of great value in future analysis involving strain-softening soils. In this case it would appear that stability would not have been endangered if the older design of vertical core, extended downwards as a cut-off, had been retained. The horizontal thrust from the clay core on the downstream shoulder, also founded on the surface layer of yellow clay, could be expected to be very similar to that from a traditional core. The fact that this shoulder remained stable suggests that a traditional design would have produced a stable dam, even with both shoulders founded on the yellow clay.
Almost all engineers who visited the site questioned the soft yellow clay layer that lay under the section of the dam where the slip first started and asked why it had not been stripped off in the preparation of the foundation. Removal of that layer of lower strength material would also have removed the areas of pre-existing shears, and undoubtedly improved the stability of a traditionally designed dam. The reason for the large boot has never been satisfactorily explained.

In conclusion I would like to defend instrumentation. The measured settlements of rows of five pegs placed across the unfinished crest from October 1983 to April 1984, combined with measurement of vertical strain and blockage in a USBR type cross-arm gauge, plus tube damage to piezometer CU1, as shown by Fig. 18 of Penman (1986), gave a clear indication of excessive strains along the path of a potential slip surface. When consideration is given to the measured pore pressures that increased during shut-down periods when no fill was being placed, it is cvident that there should have been careful consideration of stability before further fill was placed at the beginning of the 1984 season. I find it interesting that Mr Dunster (1994), Managing Director of Shephard Hill Ltd at the time, felt that he had made a mistake by not completely refusing to begin placing fill again at the beginning of the

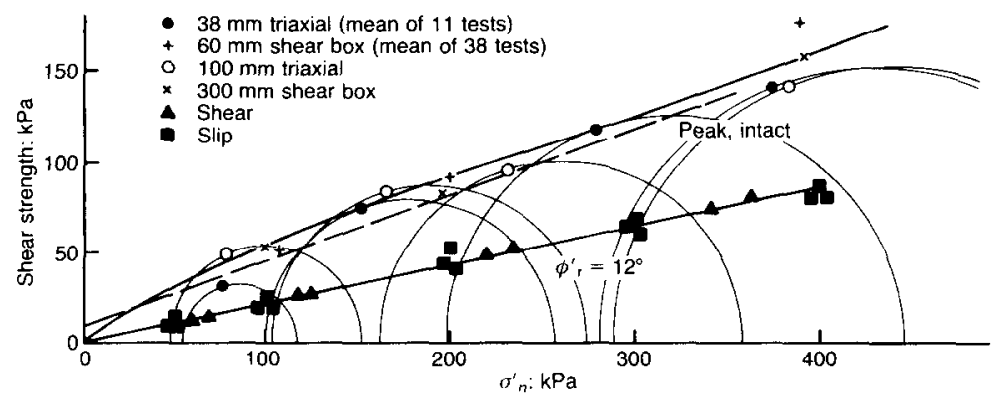

Fig. 26 
1984 season and accepting breach of contract. In fact he would then have had considerable difficulty in proving that the dam would fail if brought up to full height and, unless a new contractor had been brought in to complete construction straight away and had caused failure, it might have been argued that it would have been all right. When Muirhead failed it had almost reached full height; it was completed at that height and has continued to operate successfully for the past 50 years. Because of the very brittle nature of the soils at Carsington it might have remained stable at its 1983 height but it was much too late to save it once the large strains had taken so much of the slip surface soil beyond its peak strengths. I recall discussing with Professor Skempton at Usk Dam in 1952, at the time when pore pressures indicated that failure could ensue if it was raised to full height without some design improvement, that shearing strains in the silty fill, because it was a dilating material, would reduce pore pressures and improve stability once the beginnings of a slip surface developed; he correctly said that that was not a property that could possibly be considered in design. However, a soil that contracted on shearing, developing higher pore pressures, increased danger and had to be considered in design. This feature has been addressed by Ladd (1991).

\section{Dr D. W. Cox, University of Westminster}

The slip at Carsington should be considered in the context of a large number of existing road, rail and dam embankments where Carboniferous mudstone shale also forms the fill and foundations. These have side slopes typically between $22^{\circ}(1: 2.5)$ and $34^{\circ}(1: 1.5)$ with a common value of $27^{\circ}(1: 2)$. Compared with the dam failure at $18^{\circ}(1: 3)$ these surviving embankments are often on much steeper sidelong ground and, in the case of railway embankments (which were usually end tipped at the angle of repose of $30-40^{\circ}$ ), are at much steeper side slopes. An examination by Parsons \& Perry (1985) of $300 \mathrm{~km}$ of motorway embankments found that the Carboniferous mudstone fills were among the most stable of those used, with a $2 \%$ failure rate at $27^{\circ}$ slope and less than $1 \%$ at $18^{\circ}(1: 3)$ with mainly shallow failures.

The Authors calculate factors of safety of $1.1-1.6$ for the failed construction and suggest mechanisms such as a progressive reduction in shear strength, lateral load transfer and preexisting shear planes in both the fill and the undisturbed weathered clay foundation to explain the actual failure at such high apparent factors of safety. However, these mechanisms could also occur in the surviving embankments and similar geometry to the soft core boot may exist below

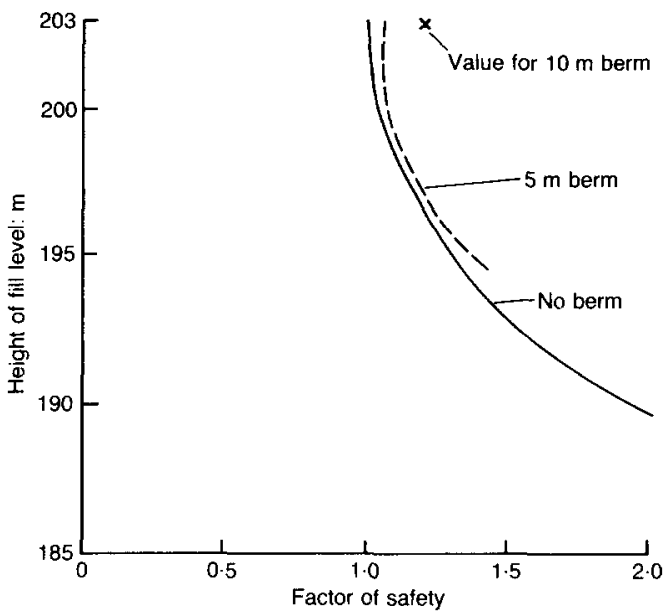

Fig. 27. Factor of safety plotted against height of embankment

some embankments where soft natural clay was left in place.

If the explanation given for the slip is accepted then these factors would apply to the other embankments. Should all new mudstone embankments be constructed at $14^{\circ}(1: 4)$ to $11^{\circ}(1: 5)$ (as the new design) and should existing mudstone embankments, particularly steep railway embankments and old dams, be reassessed?

Some other additional cause may be relevant. I would like to suggest that one of the reasons for the original embankment failure was insufficient compaction of the dry mudstone shoulders which had a low density with high air voids. When the base of the upstream shoulder was prematurely flooded the fill underwent collapse compression. In these conditions the earth tremor (which occurred just at the start of failure) would have caused some temporary liquefaction of the loose flooded base layer, and would have helped to initiate failure, assisted by further flooding due to exceptional rainfall.

The dry shoulder fill was lightly compacted and unusually loose. It is possible to backcalculate the initial air voids left after compaction as about $15-18 \%$, which may be compared with the $7 \%$ air left in the reconstruction. Some of these initial air voids were removed by dry compression of $6-8 \%$ under self-weight (Coxon, 1986). This should be compared with a typical dry compression of $1-2 \%$, as measured in the same material more fully compacted for the reconstruction (Chalmers, Vaughan \& Coats, 1993).

The strong dry mudstone softens on wetting and further compression would occur on flooding. This is roughly estimated as removing $3-6 \%$ voids, based on laboratory tests on similar 


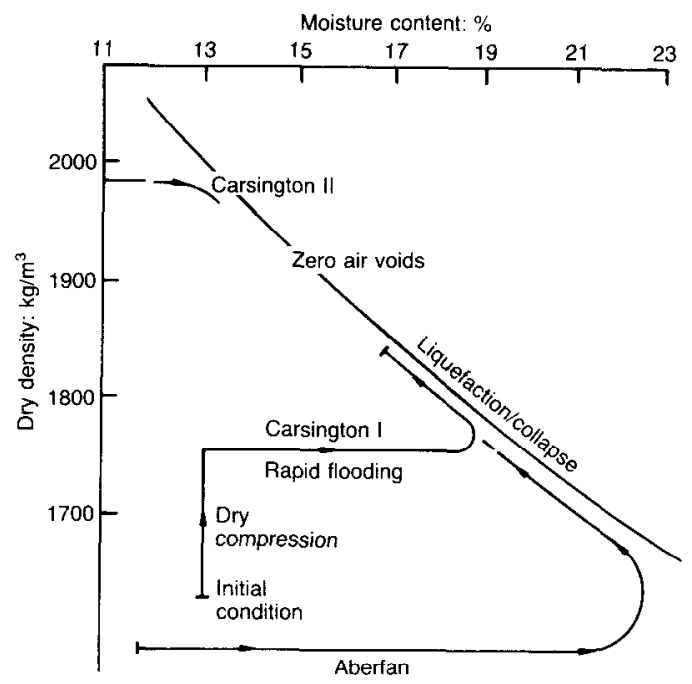

Fig. 28. Wetting path

materials (Cox, 1979). The remaining air voids of 6-9\% were filled with water, and can be determined from the change in moisture content from $13 \%$ to $16-18 \%$. The wetting path can be reconstructed from the final condition and is shown in Fig. 28, where Aberfan is also shown for comparison.

As construction proceeded the base drainage mattress collected water from the valley sides and there was no dewatering system for removal on the upstream side; hence the dry lower upstream shoulder flooded to about $4 \mathrm{~m}$ depth prematurely. This was recorded in site records and by the piezometers in the natural foundation (Coxon, 1986; Rowe, 1991). Site staff suggested that the rising water impeded compaction of the lower layers. The lowest working piezometers in the fill were still above the water level and remained dry.

The flooding caused additional collapse com- pression of the dry shoulder fill at the base. This was not directly recorded because the lowest settlement gauge ceased to work at this time, probably due to excessive movement. However, other measurements could be expected to confirm this indirectly.

The $4 \mathrm{~m}$ thick base shoulder wet layer compressed vertically by about $400 \mathrm{~mm}$ more than the adjacent boot, which was saturated at $34 \%$ moisture content and could consolidate only slowly. This differential settlement transferred a lot of extra load back on to the boot, causing an exceptional rise in pore pressure which continued to rise without further direct loading as the base of the shoulder collapsed and compressed. This was a persistent problem, for which there is, so far, no other explanation (Coxon, 1986; Rowe, 1991; Naylor, 1989). The transfer mechanism is shown in Fig. 29.

When earthworks were restarted in 1984 the embankment weight was increased by about $1 \%$ with small but uniform deformations and a large increase of $4 \mathrm{~m}$ in the boot pore pressure (at CCI) due to the transfer mechanism. The earth tremor on 30 May that year had a dynamic force of about $1 \% g$ (similar to the recent previous increase in self-weight) and caused an immediate increase of $2 \mathrm{~m}$ in the boot pore pressure (at CCI) (Coxon, 1986; Rowe, 1991).

Given the loose flooded condition of the base fill, the tremor would be likely to precipitate some liquefaction. The chain reaction of liquefaction often takes hours to develop (Seed, 1979; Akiba, 1941; Gu, Morgenstern \& Robertson, 1993). By 31 May the first exceptional movement had occurred and was recorded as a lateral movement of $40 \mathrm{~mm}$ at ch. $750,20 \mathrm{~mm}$ at ch. 875 and $15 \mathrm{~mm}$ at ch. 675. These are shown in Fig. 30, where the recorded behaviour before 25-26 May is projected forwards, and the behaviour after 1 June is projected backwards, showing that the earth tremor clearly appears to have initiated some movement, as could be expected.

On Friday 1 June exceptionally heavy rainfall

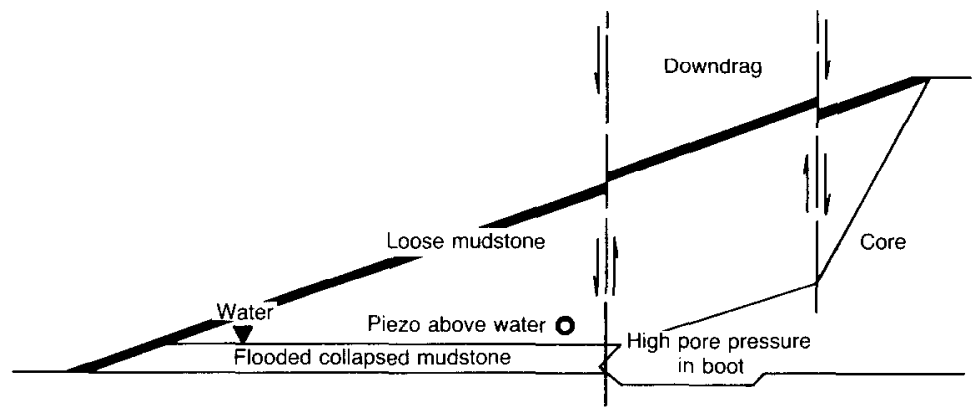

Fig. 29. Load transfer effect on pore pressure in boot 
prevented work from continuing and continued through the weekend. This will have assisted failure by entering the drains and wetting more fill at the base. Failure became obvious on Monday 4 June with tension cracks and so on.

The soil structure of mudstone fill consists of an aggregate of crushed mudstone lumps surrounded by macro air voids introduced by the bulking action of excavation and tipping, and partly removed by compaction. When the soil structure is flooded the relatively dry mudstone lumps, which contain their own saturated micro void systems, tend to swell and soften, whereas the surrounding flooded macro voids tend to collapse, expelling air or, if they are already saturated, water.

Initially two pore pressures are present: a negative one in the micro voids of the swelling mudstone lumps and a positive one in the collapsing macro voids. The processes of swelling and collapse can occur consecutively or concurrently depending on the wetting conditions. Conventional effective stress analysis may not be completely appropriate in these circumstances.

In a low density fill, if the flooded macro void volume is sufficient, and if collapse is triggered simultaneously at sufficient points (as by a tremor at Carsington or a slide at Aberfan), then the excess pore pressure and pore water created in one collapsing void will destabilize adjacent ones. The collapse process can then become selfsustaining and is called liquefaction. These events can be replicated in large-scale oedometers; the apparatus is sensitive to any vibration during the collapse process.

That liquefaction occurred at Carsington would be proven by a pore pressure being measured in the lower flooded fill. However, the nearest working piezometers (CU2, CU3 and so on) were in the dry mudstone fill at or just above the flooded level and recorded no water level before the slip (Coxon, 1986). During liquefaction the pore pressure is generated internally and would have dissipated slowly to the drainage mattress below or to the partially saturated fill above, and hence could not be recorded by the nearest instruments. The piezometers in the foundation below the drainage mattress recorded the flooding above and might have registered very slight changes during liquefaction, as the water was squeezed out of the flooded base layers, but most of this would be masked by the freedraining mattress. The other evidence that liquefaction occurred is circumstantial and related mainly to the sequence of events, which is otherwise difficult to explain.

The excess pore pressure caused by wetting and liquefaction, combined with the other factors described in the Paper, would have been sufficient

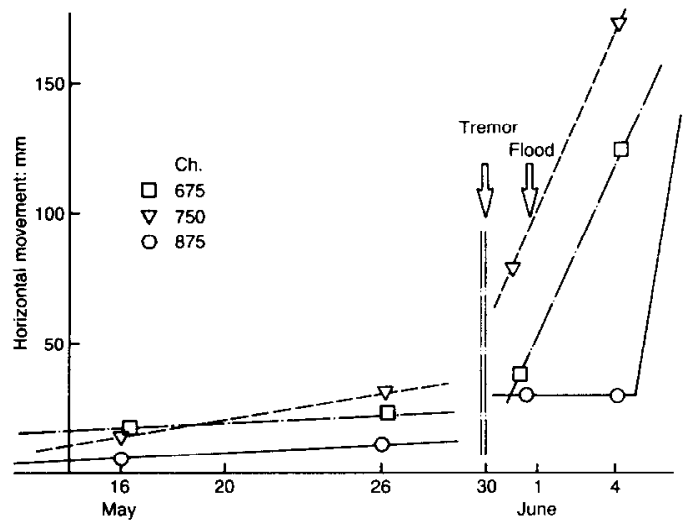

Fig. 30. Horizontal movement

to precipitate failure, but without necessitating the use of a cumulative worst case analysis. If generally applied, a cumulative worst case analysis would question the stability of a very large number of existing apparently stable mudstone embankments.

The significance for the design of future embankments is, first, that one should determine whether they are likely to be flooded at the base, by impounding, or by springs or groundwater, as in the case of Aberfan, or by temporary impounding as can sometimes occur in road embankments on steep sidelong ground. The density necessary to prevent collapse/liquefaction can be determined approximately by flooding fill in largescale oedometers. The voids/density required can then be achieved by compaction, or modification of the grading, or modification of the moisture content. Large embankment design, particularly for dams, should include a study of the secondary movements within the fill during and after construction, as well as conventional shear strength and permeability studies.

The site compaction for the parts of embankments likely to be wetted may be controlled by a method or an end result testing specification but, either way, this should achieve a density selected to avoid collapse or liquefaction on wetting, with density testing as a check, as was done for the reconstruction.

The final moisture content of the shoulder fill is of particular interest in this analysis. Values of $16-18 \%$ are given in the Paper and Chalmers, Vaughan \& Coats (1993) say that the zone 2 dry shoulder fill (at 13\%) became wetter than the zone 1 transition fill (at 24\%). Macdonald, Dawson \& Coleshill (1993) record 100 moisture measurements made on the shoulder fill when it was reused, but do not give the results. It would be extremely useful to know the final moisture content of the dry upper shoulder fill and the 
flooded lower upstream shoulder fill to help avoid this problem in future.

The Paper quotes a high initial density with $5 \%$ air voids for four density tests - the only ones on the original embankment because compaction was controlled by a method specification. The original embankment was compacted with a light grid roller which could be expected to achieve about $10-15 \%$ air voids at best, and by comparison the same material used in the reconstruction could be compacted to only $7 \%$ air voids by using a heavy vibrating roller. The four tests are therefore anomalous and may perhaps have been carried out on an area used as a haul road.

\section{F. Kennard, Rofe Kennard \& Partners}

The Authors give design parameters as $\phi^{\prime}=21^{\circ}$ for the core, $\phi^{\prime}=20^{\circ}$ for the foundation, $\phi^{\prime}=22^{\circ}$ for zone 1 and $\phi^{\prime}=26^{\circ}$ for zone 2 . However, the original design parameters used were $\phi^{\prime}=27^{\circ}$ for the core, $\phi^{\prime}=27^{\circ}$ for the foundation, $\phi^{\prime}=28^{\circ}$ for zone 1 and $\phi^{\prime}=30^{\circ}$ for zone 2 . These differences are very significant and must reflect some aspects of the interpretation and use of geotechnical laboratory test results.

In addition to the parameters being rather high, other features of the pre-failure design approach included: only circular slip surfaces were originally considered, although the geometry of the core encouraged the formation of noncircular mechanisms; when later test results for the clay core were interpreted as $\phi^{\prime}=23^{\circ}$ rather than $27^{\circ}$ no change was made in the crosssection; there was no systematic search of the critical slip surfaces; and the assessed and quoted factor of safety of 1.69 for the upstream slope was far too high for these very reasons.

A report (Kcnnard, 1983) seven months before the failure stated that a 're-design was essential'. This report was prepared not to support a claim in any way or to predict failure, but to show the Contractor's and my concern with conclusive evidence that a conventional design approach, as practised at that time on British earth dams, showed the design cross-section to be inadequate. Events have subsequently confirmed that the original design was inadequate, which was the conclusion of that report. The report included views that $c^{\prime}=0$ should be used for the clay core, and that there was sufficient evidence from triaxial test results existing before 1984 that $\phi^{\prime}$ was $21^{\circ}$ for the clay core and the boot. Both these views are supported by the post-failure investigations given in the Paper.

The correct application of the knowledge of the science and technology of dams and expertise in its use are obviously the key to the adequate design of earth dams; the evidence is that this was not done satisfactorily at Carsington in the first instance.

\section{Professor E. N. Bromhead, Kingston University}

In late October $1983 \mathrm{Mr}$ Kennard approached me to undertake a series of slope stability analyses on the first Carsington Dam embankment, which was then at the end of its second construction season, and approaching completion. There were already concerns over stability, and a small berm had been constructed over part of the upstream toe of the dam. I was to use software which I had personally coded for limit equilibrium stability analyses on both circular and non-circular surfaces-I had gone to great pains to validate this software against other codes. The analyses were made for only one cross-section of the dam, at what was about the highest section, in order to supplement stability assessments which were analysed manually in $\mathbf{M r}$ Kennard's office.

The computations were carried out over a period of a few weeks, and without the benefit of the knowledge that the dam would fail. I discussed the findings of the analyses with $\mathrm{Mr}$ Kennard on several occasions as they were progressing, and my final report to him was more of an aide-mémoire than a detailed exposition of the analyses. Most of the results were, however, presented in a tabulated form or on figures. My stability analyses served to confirm findings being made by other, uncredited, colleagues at that time and formed an appendix to Mr Kennard's report to the Contractor. Similarly, $\mathrm{Mr}$ Kennard's report was addressed to the Contractor, with the intention that it be passed on to the Engineer to form the basis of a discussion.

The first problem with assessing stability lay in the selection of soil properties. At the time of the analyses, additional tests had been undertaken, and the Engineer's original design parameters had been refined. The number of tests was pathetically small for a structure of this size, but there were significantly more results available than at the time of the original design. It was at once apparent that the tests had been made, at least in part, using an inappropriate multi-stage technique, and had almost certainly been misinterpreted. It seemed to me that at least part of this misinterpretation was in attributing more cohesive behaviour to the shoulders and less cohesive behaviour to the core. The available triaxial test data were appraised and interpreted into conventional design parameters by $\mathrm{Mr}$ Kennard's team. There were, therefore, at least four sets of possible parameters $\left(c^{\prime}, \phi^{\prime}\right)$ available which were referred to for simplicity as Eccles', Hill's latest, Hill's latest (corrected) and 
Kennard's.* These sets of parameters corresponded to what was believed to be the original design set, the revised set used by the Engineer at a later stage in construction, the revised set attributed correctly, and Mr Kennard's assessment of what the strengths really were. $\dagger$

The second uncertainty lay in the pore water pressures to be used in the analysis. An $r_{u}$ value of 0.8 had been used in the design according to Eccles. This was obviously superseded by the measured pore water pressures. In addition, it was necessary to cater for the anticipated increase in pore water pressure to completion, which I estimated, with $B=1$ for the stress increment. There were therefore at least three pore pressure conditions to consider.

Additionally, there were the three cases of no toe berm (as designed), a small toe berm (as constructed during the second season) and a larger toe berm (more in line with Mr Kennard's recommendations) to complicate the analyses. Part of the bank was known to have been built on the now-infamous yellow clay and part on a prepared foundation. The sections used in my analyses, however, all had a horizontal shoulderfoundation interface.

My first analyses, using a slip circle method permitting a search for the most critical slip circle and computing the factor of safety using Bishop's iterative method, showed conclusively that the Engineer's quoted safety factors were inconsistent with his quoted soil properties and pore pressure conditions. The critical slip circle convincingly picked out a path through the core and boot. The high undrained pore water pressures in, and the location of, the boot led to its becoming overstressed. The same effect is shown convincingly with relatively simple limit equilibrium calculations. Various other analyses contrasted the effects of differing soil properties and pore pressure assumptions and were quoted in the report.

I then concentrated on non-circular surfaces, analysed by Morgenstern \& Price's (1965) procedure using parallel inclined interslice forces $(f(x)=1)$. These approximately followed the critical slip circle in a wedge form through the core and boot, with a little variation permitted in

\footnotetext{
* Mr Eccles was the partner in G. H. Hill \& Sons, the firm that prepared the original design for the first Carsington embankment. He prepared briefing notes for visitors to the site. Some design criteria, including soil properties, were on those notes. Design parameters attributed to him were taken from those notes.

+ It seemed to me that the Engineer had assigned 'slioulder' properties to the 'core' and vice versa, as the revised properties showed the shoulder to be more cohesive and less frictional than the core materials. The so-called corrected properties simply reversed which was the core and which was the shoulder.
}

the location of the potential slide head, and then followed the shoulder-foundation contact out to the toe of the dam. These analyses enabled an estimate to be made of the effect of the toe berm. It was small, but a larger proposed berm would have made a more significant improvement to stability. The slip surfaces analysed are an almost perfect match to the eventual failure surface.

The precise location of the flat basal sole to the slip surface was of little significance in my analyses, because the effective-stress soil parameters attributed to the shoulder and to the yellow clay were essentially the same. The differences in appearance are the result of undrained pore water behaviour.

At the end of the time allotted to the analyses, I was convinced that the dam was seriously at risk, and that the construction of a substantially larger toe berm on the upstream side could reduce that risk. I undertook virtually no assessments of stability of the downstream side, only sketchy rapid drawdown calculations, and no steady seepage ones of any merit. I had already satisfied myself that for the dam to be completed safely, considerable modification to the cross-section was needed. $\mathrm{Mr}$ Kennard's main recommendation stated unequivocally that 'a revised design was essential'.

It seemed to me that in view of Mr Kennard's reputation, the other parties would heed his observations far more readily than they would my results, attempting as they did to permutate and combine all the factors. It seemed desirable to word the report in the restrained, conciliatory tone that is used when one is not trying to provoke an argument. The reports therefore all fail to convey the strength of conviction that we all needed to discuss the potential for instability. In future, I will be more blunt.

Subsequently, I had sight of critical slip surfaces considered by the original designers to assess stability, some of which were obviously unrealistic and did not cover the obvious critical slip surfaces through the core and boot (Fig. 31). A boot provides for the three-wedge slip surface shown as an inset, which is significantly less safe than the two-wedge shape with a conventional narrower core. $\ddagger$

With the benefit of hindsight, it is possible to find defects of detail in the analyses I undertook so hurriedly in 1983 . However, I was unaware at that time, and failed to appreciate for some time

$\ddagger$ Figure 31 is not exactly true to scale, but a copy of a reduction of a poor dyeline copy. In late 1983 a drawing showing the latest stability analyses undertaken by the Engineer was handed to Mr Kennard. The drawing was shown to me. It had no number, and was obviously a working sketch. I was informed that the deep slip surface was the most critical one that the design team could find; it had a factor of safety of $1 \cdot 2$. 

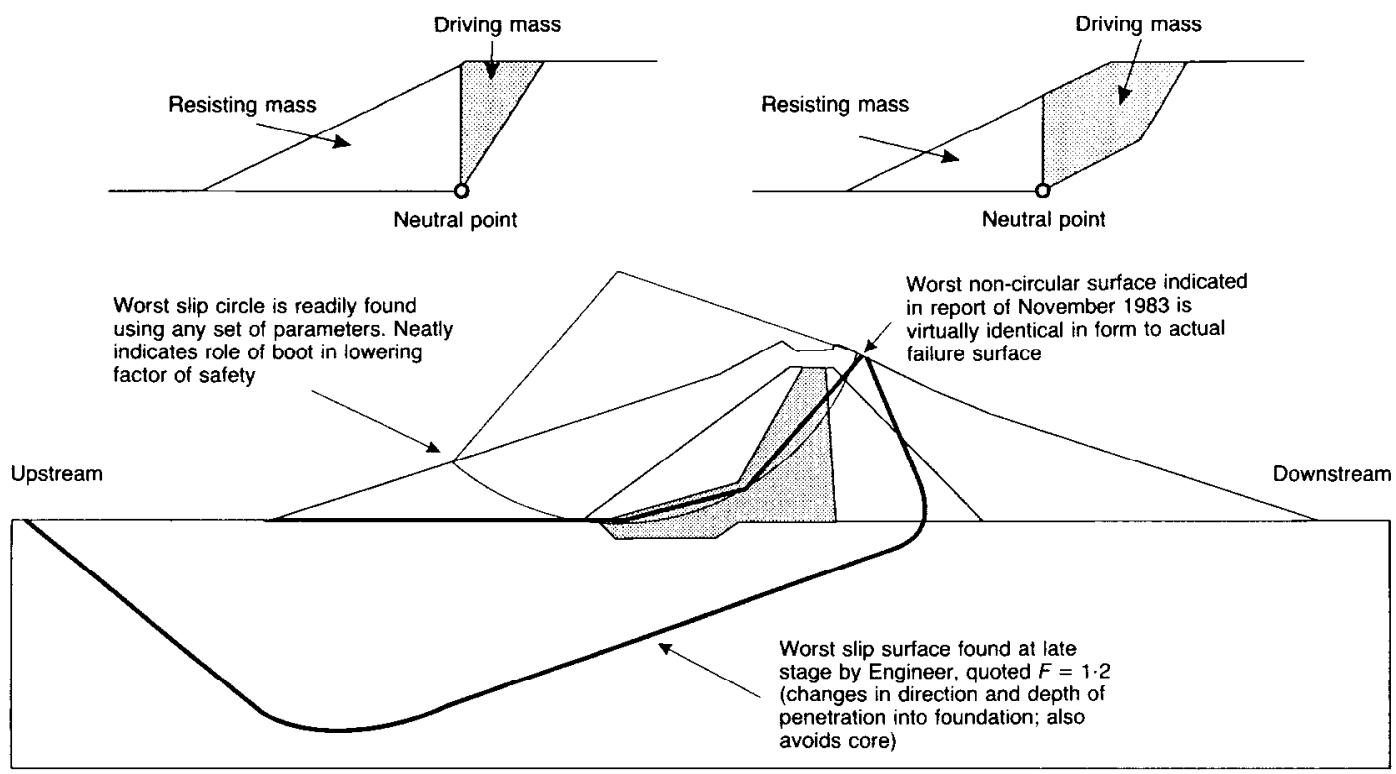

Fig. 31

subsequently, that the shoulder-foundation contact on yellow clay at the section where the dam failure started actually sloped appreciably in a direction which assisted slipping. This section also had a negligible berm, which was placed only over the sections where the dam was highest. It is not surprising that instability started there.

In summary it may be said that the failure of the Carsington embankment took place because its designers

(a) failed to make sufficient tests of the correct type, interpreted adequately and in accordance with existing good practice, to assess the nature of the foundation and fill material and to yield acceptable and conventional soil properties

(b) analysed stability in inadequate and unconventional ways

(c) used geometric features in the design which promoted instability

(d) failed to amend the design with regard to test data and instrumentation readings which became available as construrtion proceeded

(e) appeared not to accept the validity of warnings from prominent and experienced authorities

( $f$ ) failed to appreciate evidence of substantial deformations during the winter shutdown, such as crest settlements and malfunctioning instruments.

It is not surprising that the dam failed.

I was convinced at the time, and remain convinced, that a dialogue established in the winter of 1983-84 leading to changes in the cross-section of the dam would have enabled it to have been completed safely during the 1984 construction season, saving virtually all the costs of investigation, redesign and reconstruction.

Professor Skempton addressed the British Geotechnical Society on the subject of residual strength on the day the main part of the failurc occurred (Skempton, 1985a). He stated categorically that brittleness in clays was not a problem in rolled clay fills. He recanted from that very rapidly. However, it was at that time a widely held view. I was taught about it in 197172. I changed my view partly as a result of seeing the Carsington multi-stage tests. However, with an adequately designed cross-section, the brittleness of the materials involved and their loss of strength post-peak would not have been a problem.

In the post-failure dig-out at Carsington no continuous slip surfaces were found beneath the basal slip predicted by my stability analyses of late 1983. This was also the situation in the postfailure dig-out at the Selborne controlled slope failure experiment. Perhaps the formation of a shear surface with its reducing shear transfer capacity insulated the underlying beds from the effects of what was happening above.

\section{J. A. Dunster, formerly Shephard Hill \& Co. Ltd}

The Paper does not state that the original failure need not have occurred and should never have been allowed to happen. 
In the summer of 1983 , nearly a year before the collapse, the Contractor raised with the Engineer doubts regarding the stability of the embankment, on account of the soft surface clays which were being left in position under large areas of the dam shoulders. These doubts were followed by an embankment stability report by the Contractor's consulting engineer (Kennard, 1983) which was submitted to the Engineer. The main conclusion of this report was 'that further analyses are necessary and a revised design is essential, to be agreed amongst the parties, so that the embankment can be completed in 1984 with safety and confidence'.

Despite repeated requests by the Contractor, no meetings to discuss this matter were held between the parties during the winter close-down of 1983-84. Ultimately the Engineer wrote to the Contractor giving instructions under clause 13(1) of the ICE Conditions of Contract (Institution of Civil Engineers, Association of Consulting Engineers \& Federation of Civil Engineering Contractors, 1973) to recommence construction of the embankment in April 1984, having made no alteration to the design, even though there were indications that a slip zone was occurring.

My biggest mistake, having written to the Engineer in March 1984 saying that work would not recommence on the dam construction in 1984 until the design in question had been resolved, was not to defy this Engineer's instruction and to be in breach of contract. This would have forced a show-down meeting between all parties. Unfortunately, I decided not to have a breach of contract.

After the failure, the involvement of the insurance companies and legal advisers of the various parties made open and frank discussion very difficult. As a result, huge sums of money were spent and inordinate delays occurred which could have been greatly reduced, as the basic cause of and responsibility for the collapse was known at the time by the parties concerned.

Fortunately, the Carsington failure has resulted in the appointment of review panels of experts in the construction of major dams, so that a recurrence of failures of this type should be avoided.

However, the other aspect involved at Carsington - the breakdown of dialogue between the parties concerned-will continue to occur and cause problems on future major schemes, and may again affect the safety of schemes and the public. Perhaps the use of review panels of experts needs to be considered in a wider context to include all major civil engineering schemes involving the safety of the public.

\section{P. W. Rowe, Consultant}

The Authors have published a number of important observations, not least of which is that, 'A small berm was placed at the upstream toe as compensation for an increased rate of construction in August 1983.' Moreover they have corrected the vertical strain data in Fig. 10 to conform with Fig. 7(a), Rowe (1991) noting that the gauge CS1 then became blocked. The real vertical strains developed during the 1983-84 shut-down at the centre must have been larger. The bank was then only $22 \mathrm{~m}$ high and yet the maximum core strains had already equalled those developed only at ch. 705 by as late as 4 June 1984 after the bank had reached $29.6 \mathrm{~m}$ in height. Such a massive lead at the centre is not yet mirrored in the FE analyses although the Authors do now show a greater percentage weakening at the centre (Table 6) than at the side (Table 4). During construction concern related to the centre.

The purpose of this discussion is not to reiterate Rowe (1991, 1992), which might best be read with the Paper, but rather to look to the future. Skempton \& Vaughan (1989) made a very important statement - 'the failure is not predicted by the (limit) analyses ...' and with Potts, Dounias \& Vaughan (1990) they have been using FE techniques to treat progressive failure. The analytical problems, even under idealized conditions, are immense and currently are engaging the minds of leading numerical analysts internationally. As the decades go by and both computers and techniques advance, Carsington will be analysed repeatedly. The process has already started, (by, for example, Chen et al., 1992), and in so far as Binnie (1978) reconsidered the Dale Dyke failure of 1864 , publications on Carsington may continue for over a century.

When modelling the centre, where there was an agreed unknown number and distribution of built-in plant shears, it is necessary to vary the shear distributions and fill stiffness until all of the following field observations are recovered using the same input parameters, namely

(a) total stress lateral transfer in 1982 at bank level $182 \mathrm{~m}$ (Rowe, 1991, Fig. 18) after further raising and insertion of the berm in August 1983 at level $193 \mathrm{~m}$

(b) the vertical strains in the core during 1983-84 at level $197.8 \mathrm{~m}$

(c) the vertical total stress reversals in the boot (Rowe, 1991, Fig. 17)

(d) the vertical displacements found by Penman (1992) in the crest

(e) the internal overall displacements and strains from core to toe.

With regard to the unmeasured displacements before level $193 \mathrm{~m}$, Babtie Shaw \& Morton \& Skempton (1986) published a relation $\Delta=0 \cdot 2$ $(H-5)^{2}$ and, when $H=22 \mathrm{~m}$ at level $193 \mathrm{~m}$, 
$\Delta=58 \mathrm{~mm}$. The value deduced independently by Rowe (1991) was $65 \mathrm{~mm}$. In Fig. 11 the Authors fit their FE analyses to $148 \mathrm{~mm}$ and they state that 'At ch. 875 movements predicted by a matching FE analysis are larger than those measured, probably due to shortcomings in the modelling of the stiffness of the fill in the finite element analysis (Potts et al., 1990)', so it may prove helpful to fit the smaller displacements at level $193 \mathrm{~m}$.

Success of anaytical fit to $(a)-(e)$ will also require the development of a three-dimensional progressive failure model to examine, while using similar distributions of plant shears in the boot across the valley, the transfer of load longitudinally northwards, together with the progressive development of local strain along the planes of weakness. Small overall longitudinal strains based on berm head displacements do not identify the larger internal movements or strains near the boot (e.g. fig. 20 of Potts et al., 1990). Moreover, even a longitudinal strain of $0.1 \%$, twice cited by the Authors, can mobilize about $7 \%$ of peak strength with stiffer mudstone and under high initial stiffness in interslice shear at low interslice strain.

This is shown clearly by field measurements in Fig. 32 which relate to a case where a slope A started a slip mechanism on completion which was arrested by the placing of a berm. At a longitudinal distance of about three times the slope height, the heightening of a continuation of the slope at B started a slip at B. After a settlement of the crest at $B$ of $0.2 \%$ of the slope height at $B$ the slip at $A$ was reactivated even with its berm in place, and the whole length A-B moved until the

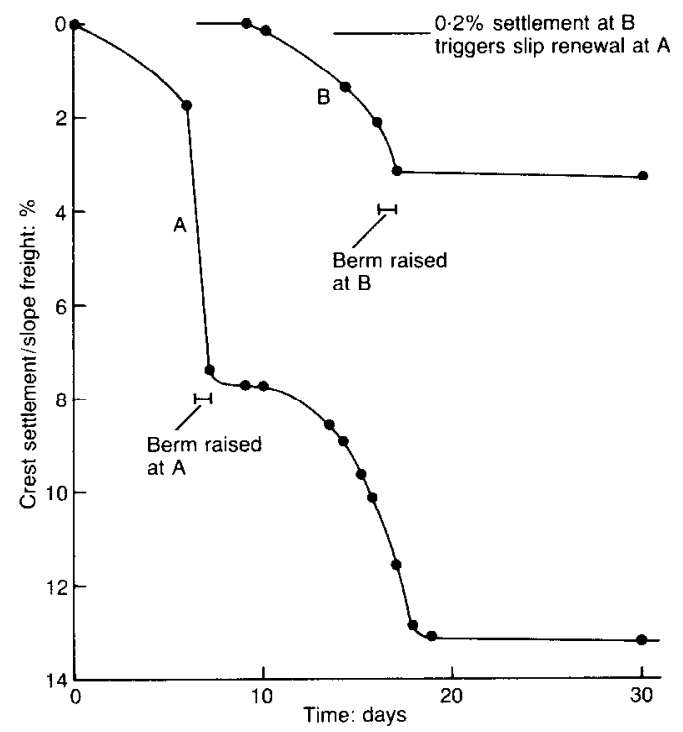

Fig. 32 berm was extended to $B$. The explanation is that the smallest movement at $B$ relative to $A$ reversed the direction of the whole of the side shear on A, from one of support to one of drag, and was sufficient to cause the failure to spread along the length of the slope. The slips passed into the foundation which was the same material throughout.

Action and reaction are equal and opposite. If the north side dragged the centre by $10 \%$ of $F$ (Babtie Shaw \& Morton \& Skempton, 1986) when longitudinal shear strains increased eventually on a highly non-linear path to $1 \%$, then the centre resisted the failure at ch. 705 by $10 \%$ on a similar highly non-linear path. However, until 21 May the centre led the side. If the Authors cannot understand or accept the initial stiff interslice shear stress-strain relation before 21 May and prefer to regard the shear drag from the centre as zero (not agreed), then from their own writings there must have been at least $10 \%$ stress reversal, or build-up in a direction to support the north side during the period following 21 May. Unlike normal, single area failures, that support developed only after the critical state was reached. It was not already there. Its development, and side resistance strengthening, balanced the development of shear surface developments and weakening in the yellow clay. Failure occurred on 4 June when the normal maximum side resistance had been developed. By that date a proportion of the shear surfaces had developed progressively in the yellow clay that fit simple back-analysis on 4 June. Taking the relevant boundary shear directions into account, critical state was recovered on 21 May (Rowe, 1991).

Thus when analysts address ch. 705 a vital ingredient of any two-dimensional model has to be the reversal in the direction of side shear at the time of initiation of failure (Fig. 32). A threedimensional model should recover this automatically. In the case of a single slope failure, side shear develops with movement up to the point of failure, and consequently a tension crack develops at the time of imminent collapse. That was the reasonable experience on which the Authors relied in 1984. But Babtie Shaw \& Morton \& Skempton (1986) noted the rapid acceleration of creep at $\mathrm{Ch}$. 675 between 25 May and 4 June', which can also be deduced at ch. 750 in their Fig. 8.13. In section 8.11.1 they stated, 'No clear signs of instability until after 25 May'. It is therefore already an important matter of agreement that instability had clearly started by, at the latest, 25 May; Rowe (1991) put the date more precisely at about 21 May, even though at the time impending acceleration was indeed less clear between 21 and 25 May. That acceleration is not explained by embanking, not just because banking had 
ceased from the north side up to ch. 775 by 21 May, as shown on the detailed site records, but also because movement broke away from the Authors' previous relation between displacement and height of bank from 21 May.

The fundamental, very high, initial stiffness on the reversal of side shear stress direction can be seen from the rapid reduction in load with the slightest reversal of shear direction in a shear box. Recently a sugar silo containing a $12000 \mathrm{t}, 45 \mathrm{~m}$ high store of sugar suffered cracks from top to bottom in the walls when the silo, while full of sugar, was subjected to an angular distortion of the foundation slab; there was commensurate warp and vertical movement of the walls of only $0.04 \%$. The longitudinal, radial, vertical load transfer within the confined sugar under this seemingly infinitesimal distortion due to adjacent foundation loading interaction, reached about $25 \%$ of the total sugar load downdrag on the walls (Gilbertson \& Rowe, 1988). It is an identical mechanism, in principle, which explains where support came from between 21 May and 4 June at Carsington when the $40 \%$ shears were being developed. Twice the Authors have sought to deny the interactive mechanism, relying each time on a rough estimate of the small longitudinal strain based on overall displacements and one direction only, without reference to soil stiffness and stiffness on reversal. All the literature on structure-soil-structure interaction cannot be ignored in that way. What do the Authors think was happening between 21 May and 4 June, having regard to all associated movements? If $40 \%$ pre-existing shears had been present in the yellow clay before $21 \mathrm{May}$, were no more formed while ch. 705 was accelerating? How do they explain the ultimate, relative, scarp heights?

Professor Skempton has long taught the limits of zero and $100 \%$ development of residual shear. The concept of a natural, pre-existing, intermediate condition is without precedence. Potts et al. (1990) demoted the effect of $40 \%$ shears to one of $6 \%$ on the factor of safety which they stated to be consistent with the uncertainty of their analysis, so it is becoming more difficult to follow in that context the extent to which which new precedence is so vital to mechanism. Independent numerical analysts should trace events up to 21 May and find the acceleration from that date and examine what was happening between 21 May and 4 June, rather than always start with an inviolate model having $40 \%$ pre-existing shears (i.e. before 21 May) in the yellow clay.

Analysts should also take account of the special nature of the zone II fill at its base in the slip area of the valley centre. The material reported by Soil Mechanics Ltd through which the main slip passed at TP825 was described as 'Gen- erally stiff friable dark grey clay with generally much gravel and cobbles of angular to subangular Mudstone and occasional sandstone. Occasional rounded quartz gravel towards the base. Below approximately 167-168 m AOD occasional brown mottling, occasional, becoming more frequent with depth, pockets of firm-stiff yellow brown mottled light grey clay with occasional subangular sandstone gravel. The pockets are $10-100 \mathrm{~mm}$ thick generally up to 250 $\mathrm{mm}$ occasionally to $500 \mathrm{~mm}$ long containing extremely closely spaced highly polished randomly oriented discontinuities up to $50 \mathrm{~mm}$ extent.'

Where the Authors describe all material in the outer shoulder as zone II fill and show in Table 2 the water content $w$ as $14 \%, 18 \%$, consistent with mudstone won from $6 \mathrm{~m}$ depth and brecciated mudstone (Table 1), the reader may not suspect that the material described by Soil Mechanics Ltd is more consistent with a mixture of $b_{1}, b_{3}$ and $b_{4}$ in Fig. 5, i.e. more like that specified for zone I fill. The borrow pit records prove that the matcrial won on 27-28 July 1982 at the start of work at the centre was taken from levels between $2.4 \mathrm{~m}$ and $6 \mathrm{~m}$ depth, and consistent with the material as found in place. On and after 29 July 1982 that material was rejected. Table 1 indicates $w=27 \%$ for the grey clay, apart from occasional $b_{1}$ with $w=38 \%$; such material as described in place could only have been at least $4 \%$ wet of optimum water content when compacted. Moreover, as proved by site records, the drainage blankets were flooded with artesian water directly the first layer had been laid (Rowe, 1986). It should be noted that deep-seated control of artesian pressure by pumping later formed an integral part of the reconstruction.

These facts also explain the reason behind the Authors' statement that, 'No sheared surfaces were observed in the mudstone fill at Carsington except in close proximity to the main slip surface.' However, they continue to say that rutting, with curved surfaces 'was never seen in the zone II fill which was much stronger' and that cannot apply to the basal fill laid on 27-28 July 1982 through which the slip progressed; indeed a typical curved shear is shown by fig. 9 of Rowe (1991). These facts may also lower the relevant value of $\phi^{\prime}$ by about $2^{\circ}$ along the central basal progressive shear surface.

Professor Skempton had a very onerous brief. He was appointed on 7 June 1984 to report within four months, and he did so on 3 October with a 60 page report which must have been in preparation by mid-September. Naturally he started exploration around ch. 705, where the tension cracks had first appeared. The pit TP825 at the centre was at the base of a major cut through the fill, only completed on 3 September, 
and the multiple shears from the piston samples taken at the head of the boot were not available until about mid September. After inspection of TP825 it was not clear why several shear planes were in the base of zone II rather than elsewhere, and certainly no one could then see the full significance of all the plant shears being gradually revealed. Back-analysis at ch. 705 for 4 June exposed a lower $\phi^{\prime}$ than critical state in the yellow clay to fit simple limit analysis and Babtie Shaw \& Morton \& Skempton (1984) wrote, 'the Yellow Clay is weakened by the presence of preexisting shears and these must have played a significant part in the failure'. The word pre-existing, relative to 4 June analysis, is agreed. It is whether these shears were the cause or the result of failure that provides a challenge to independent FE analysts.

Figure 17 represents a site plan of the foundation materials as found during the reconstruction. It agrees with fig. 1 of Rowe (1991), which was based on site records of the materials found during preparation of the formation. From both sources yellow clay occurred inter alia between ch. 970 and ch. 1040. Contrary to both sources of factual record, the Authors allege that no yellow clay occurred over that area. In fact between ch. 970 and ch. 1040 part of the slip surface passed through a layer of remoulded clay on the foundation surface and not through the yellow clay.

During the removal of the embankment the Authors cite just two areas where 'solifluction shear surfaces' were observed in the yellow clay 'outside' the slide area. The main one, where a surface was 'about $10 \mathrm{~m}$ by $20 \mathrm{~m}$ ' is shown under the southern end of the slip (Fig. 17). It had sheared grout holes used to consolidate the tunnel-hardly a glacial activity. Otherwise only 'one very local area' was found downstream and even then one is not to know what recent site activities had taken place in that location.

To build a whole explanation of the embankment failure, like an inverted pyramid, on one concept, without precedence, in disregard of correlation with many of the site records, is understandable under the pressures of AugustSeptember 1984; to maintain the original working hypothesis in the face of all new evidence would appear to differ from the flexible review methods of Terzaghi, even after he had committed himself to writing, as so ably described by Bjerrum (1960).

The significance of the berm being placed to counter the contractual limit to embanking height in 1983 is that, had it not been placed when it was, the leading central movements would shortly have led to the identification of a major problem, whether diagnosed to be due to plant shears or not at the time, and led to the raising of a massive berm throughout the valley rather than the token berm local to the centre. It is understood that in any event the intention was to place an enlarged berm before impounding.

The significance of the plant shear in the base of the fill across the centre of the valley and in the boot right across the valley, when taken in conjunction with the unfortunate token berm at the centre, is that had the plant shears not been there, at any chainage, events would surely have been different. With a solid embankment at the centre the peculiar unstoppable movement from 21 May 1984 would not have developed as it did, even supposing, with no plant shears, the critical state had been reached in the yellow clay. A berm over the more limited valley side might well have been placed in time to prevent what would otherwise have been a local valley side slip, but the spectacular spread of failure right across the valley and up the southern flank, which made Carsington the event it was, would never have happened.

\section{E. H. Taylor, Mott MacDonald}

I cannot speak on behalf of G. H. Hill \& Sons, the designers of the dam, but I wish to respond to the comments made that the failure could have been foreseen.

If any reasonable set of parameters is taken for the original design, together with the parameters which were ultimately found from the exhaustive site testing, it is found that there is a high factor of safety from conventional stability analysis of the original dam.

Calculation of the factor of safety by using conventional analysis, with the peak strength parameters as determined from the site investigations and the actual pore pressures measured during construction, shows that there are high factors of safety for the original construction (Fig. 33). At the highest section of the dam the factor of safety is 1.55 .

The Shephard Hill report (Kennard, 1983) said, 'The results of the slip-circle analysis of the present state of the dam, i.e. using measured pore water pressures, show a surprisingly high safety factor. It has been possible to slightly refine this using non-circular surfaces. Using the Eccles or either set of Hill's latest parameters it would appear to be possible to raise the dam to its full height without fear of collapse, without the construction of a berm. This feature merely strengthens both the dam and the above conclusion. Caution must, however, be exercised. Kennard's parameters, much more representative of the shear strength parameters assumed for other dams built of such materials, yield much lower factors of safety. Indeed, foundation failures were indicated as being almost imminent for the 


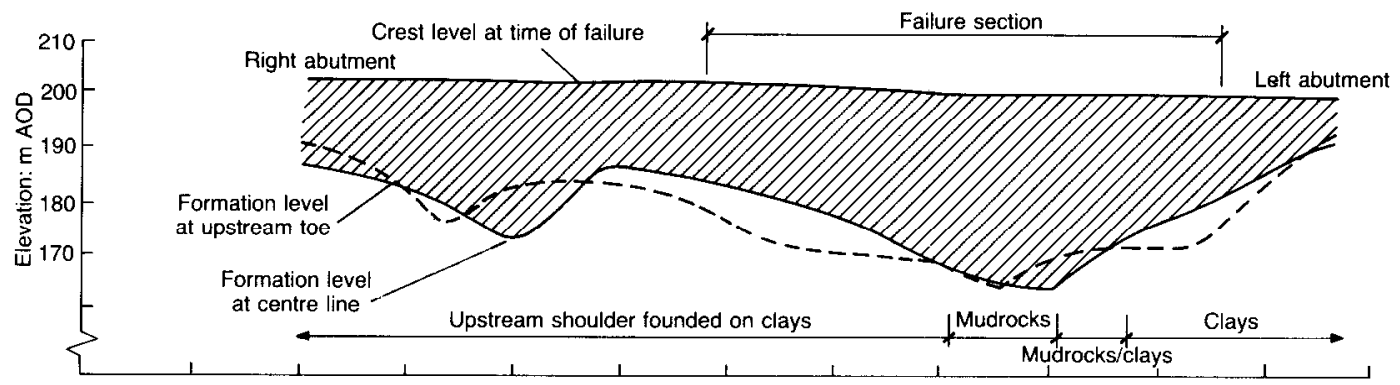

(a)

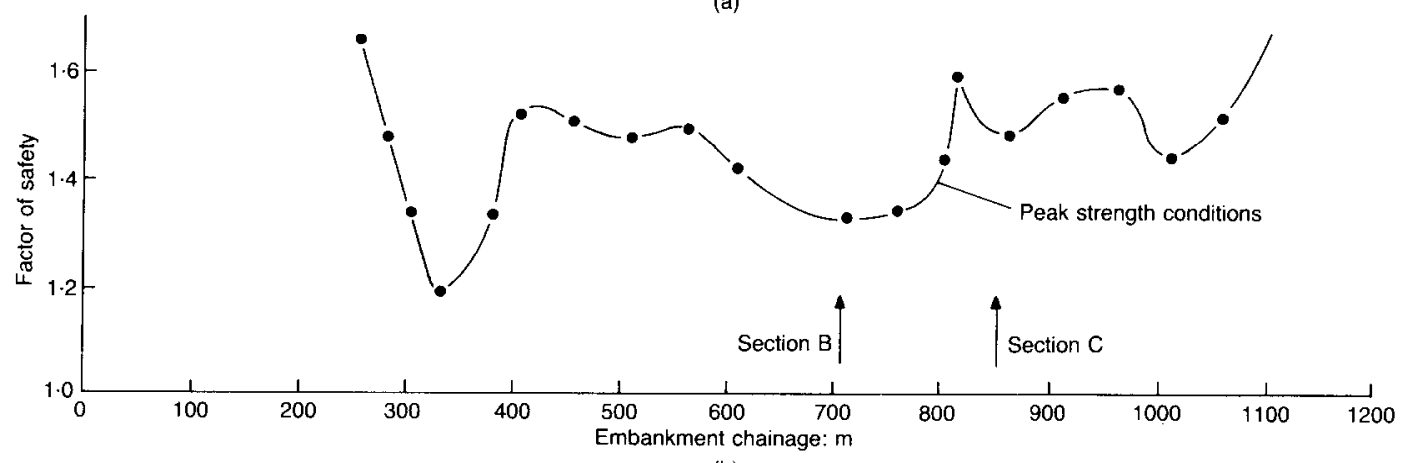

(b)

Fig. 33. Factors of safety using peak strength parameters from post-failure testing and actual pore pressures before failure: (a) longitudinal section along dam axis looking upstream (vertical scale $=5 \times$ horizontal scale); (b) factors of safety for upstream shoulder

present state had the berm not been placed, and probable if the dam had been raised to full height without it. This could be slightly less critical if the foundation shear strength parameters were greater at depth. The berm in this case is an essential prerequisite for safe completion of the dam.'

This quote shows that the report could be taken in two ways, and I return to my point that, using conventional limit equilibrium analysis, the factor of safety was high, and higher than one would normally expect for the duringconstruction condition. After Coxon's (1984) interim report, I pointed out to him that the question of solifluction shears in the clay does not adequately address the problem of failure, because there are in fact two sections of the dam to consider: the section which is on clay and the section which is not. The point that must be considered is that the failure section is very long and it covers both the mudrocks and lengths of dam which are on the clays.

It was only by finite element analysis carried out by Dr Naylor in early 1985 (and given to $\mathrm{Mr}$ Coxon in June 1985) that it was possible to show that in fact the original reports and papers by Coxon (1984), Babtie Shaw \& Morton \& Skempton (1985) and Skempton \& Coats (1985) could not explain the failure of the dam, and that the failure had to be explained in terms of internal overstressing whereby the deformations of the dam reduced the strength of the clays from the peak to what was called a plateau strength, which was above the residual. The failure could not have been predicted by any normal means. This is shown by the fact that for more than a year after the failure none of the many investigators was able to explain the failure by calculation when using realistic parameters.

\section{Authors' reply}

Dr Penman has given further information concerning his initiation of the site investigation. He also asks about the effect of undulations of the shear surface in the yellow clay. Undulations in the direction of shear were taken into account as discussed in the Paper. The effect of undulations (slickensides) at right angles to the direction of shear can also be significant. A section of the undulations at Carsington, taken from $\mathrm{Dr}$ Penman's sample, is presented by Vaughan (1993). Such undulations increase the strength of a shear surface, unless the lateral stress $\sigma_{2}$ is zero. The increase in shearing resistance is easily estimated if the normal effective stress on the actual undulating shear surface is estimated from the stress normal to the plane of the shear surface and the lateral stress. The total shearing resist- 
ance is then obtained by integration along the shear surface. The effect is found to be small unless the undulations are severe. For the undulations at Carsington the effect could only be a few per cent, and it had already been taken into account by tests performed on the actual surface. Thus it was ignored.

Mr Kennard comments on significant differences between strengths assumed in the original design and those deduced from the post-slide investigations, and on the factor of safety quoted by the original designers of 1.69 for the valley centre section, which he says was too high.

The foundation strength of $\phi^{\prime}=20^{\circ}$ attributed to us is for the intact peak strength of the yellow clay (with $c^{\prime}=10 \mathrm{kPa}$ ). The value of $\phi^{\prime}=27^{\circ}$ (with $c^{\prime}=22 \mathrm{kPa}$ ) attributed to the original designers is presumably for weathered mudstone, as the yellow clay was not recognized as a separate stratum at that stage. Testing performed for the new embankment indicated a minimum peak strength for the weathered mudstone of $c^{\prime}=15 \mathrm{kPa}, \phi^{\prime}=21^{\circ}$. Strength along the bedding planes could be as low as $c^{\prime}=0, \phi^{\prime}=16^{\circ}$, but the superficial bedding was too disturbed to allow sliding along it.

There has been some discussion of the validity of the method used by the original designer to obtain his factor of safety of 1.69 (Coxon, 1986). Irrespective of how this figure was obtained, we think it should be noted that it is not very different from the factors of safety obtained from analysis of the actual rupture surface at ch. 850 in the valley centre, using the peak intact strengths measured during the extensive post-slide investigation. These are given in Table 5. Similar results are quoted by $\mathrm{Mr}$ Taylor. With measured pore pressures, the factor of safety is 1.60. Putting $c^{\prime}=0-$ a conventional assumption of the time for stability analyses in clays - and with values of $\phi^{\prime}=21^{\circ}, \phi^{\prime}=22^{\circ}$ and $\phi^{\prime}=26^{\circ}$ for the core, zone I and zone II fills (the same values as in the first line of Table 5) gives a factor of safety of 1.38 (not given in Table 5). Thus the slide cannot be explained by conventional limit equilibrium analyses of the valley centre, even when the strength measured in high quality tests is used. It would have been necessary to reduce design assumptions substantially below the measured strengths (even with $c^{\prime}=0$ ) for a factor of safety of unity to be obtained.

Professor Bromhead, Dr Penman, Mr Kennard and $\mathrm{Mr}$ Dunster discuss events preceding the slide to which we were not party and on which we cannot comment. Professor Bromhead, Dr Penman and Mr Kennard also comment on the design as it existed in 1984. Our assessment of this design is as follows.

The slopes adopted were within precedent for fill from carboniferous mudstone, but they were towards the steeper limit of this precedent, although the mudstone at Carsington is on the lower bound of properties for such fill, and is inclined to break down to a clay. The slopes would be unusually steep for an embankment of clay fill.

In the long term, and in the short term if consolidation of the fill and foundation is rapid, the stability of embankment dams with cores of conventional width is governed by shallow sliding of the external slopes, rather than deep-seated sliding involving the core, however wet and weak this is. Thus the adoption of sensible slopes usually guarantees stability. Notwithstanding the steep slopes adopted and the rather weak core, this was true of the downstream slope at Carsington.

Short-term undrained stability problems are well known, but neither the foundation nor the general mudstone fill of the original embankment at Carsington generated excess pore pressures which wcre critical to short-term stability.

As pointed out by Professor Bromhead, the short-term stability problem arose at Carsington because of the inclusion of the boot at the base of the core, which was weak, generated high construction pore pressures, and was too thick to consolidate during construction. This made shortterm, end-of-construction, deep-seated sliding the critical mode of collapse of the upstream slope.

Deep-seated sliding, and the abrupt change in strength between the boot and the yellow clay/ mudstone fill which promoted stress and strain concentration, made progressive failure a major factor in the collapse.

There were two types of slide at Carsington: one through the in situ yellow clay left on the abutment slopes, and one, in the valley centre, through the mudstone fill. Both materials had the brittle shear behaviour necessary for progressive failure, and both failed in the drained state. It was perhaps fortuitous that the yellow clay on the abutment failed first; the mudstone fill in the valley centre was close to doing so.

The mechanism of progressive failure has been discussed in the literature since the late 1960s, but no means of quantifying it was available in 1984 , and there was no unequivocal field evidence from which the magnitude of its effect could have been deduced. Thus the extent to which it could have been allowed for at Carsington at that time was a matter of engineering judgement. This judgement could have involved some conservatism because of the known history of instability in plastic clays, tempered by the extent to which this history was thought relevant to Carsington. It would have been more obvious to make allowances for the yellow clay than for the mudstone fill. To the best 
of our knowledge, the yellow clay was not recognized and addressed as a separate foundation stratum with a lower strength prior to the slide.

As already discussed, limit equilibrium analysis, properly performed, using the field data from instrumentation available in 1984 and soil data as might have been obtained by a supplementary site investigation equivalent to that performed after the slide, and addressing the yellow clay, would have indicated factors of safety close to or at the lower bound of acceptability for end-ofconstruction conditions, even without any additional conservative allowances such as might have been thought appropriate for the soil types involved. This conclusion was drawn by Professor Bromhead.

There was evidence of unusually large movements at the end of the 1983 placing season. These factors should have indicated that there was cause for concern, and did indicate this to some of those involved, as described by $\mathrm{Mr}$ Dunster. However, neither the results of new analyses nor the measured movements would have indicated unequivocally that collapse was imminent.

Had action been taken, a further calculation would have indicated that, unless impounding had been delayed until the boot had consolidated, stability would be more critical with the reservoir filled to about a third of full depth. A full site investigation should have revealed the deterioration of the drainage material due to acid attack. The most likely measure to be adopted to improve stability would have been to add a larger berm. However, subsequent FE analysis (Dounias, Potts \& Vaughan, 1989; Vaughan, 1991) has shown that, because of the progressive failure mechanism, the improvement in stability produced by adding a berm would have been much less than was indicated by limit equilibrium analysis. What measures might have been taken, and the extent to which they would have ensured satisfactory future performance of the embankment, can only be a matter of conjecture.

It is by no means evident to us that a reassessment of stability in 1984 would have resulted automatically in measures being adopted which would have been sufficiently conservative to give an embankment with conventional reserves of stability. The adoption of a review panel, as discussed by Mr Dunster and as was done for the reconstruction of the embankment, would certainly have helped.

Perhaps the slide is best attributed to the combination of an unconservative design with an unsuspected and unquantifiable problem. The extensive studies promoted by the dam's owner have played a major role in quantifying this problem and in reducing future uncertainty in dealing with it. We have some sympathy with Professor Bromhead's and Mr Dunster's comments, but we believe it would be incorrect to attribute the cause of the slide wholly to evident defects in the design. It would also be unwise, as it might prevent some of the proper lessons from being learnt.

In the lecture on residual strength referred to by Professor Bromhead (Skempton, 1985a), it was stated that residual strength was generally not relevant to first-time slides or to the stability of clay embankments. Brittleness (which depends on residual strength), progressive failure which occurs due to brittleness, and the first-time slides in which brittleness operates were not discussed. However, the analyses stimulated by the Carsington slide (Potts, Kovacevic \& Vaughan, 1994) have shown that plastic clay fills can be subject to progressive failure to a surprising extent, given their rather flat stress-strain curves. Professor Skempton welcomes this opportunity to correct his 1985 statement: residual strength can indeed play a part in first-time slides in clay fills and cuttings.

Dr Cox comments on the properties of the mudstone fill, and on the implications of the Carsington slide for suitable slopes for highway embankments formed from mudstone. We suspect that, probably, there are none-unless the highway embankments are unusually high and contain a core and boot. The stability of highway embankments is usually controlled by superficial material degradation and shallow sliding, and by the swelling which occurs with time in plastic clay fills. Evidence from surveys of highway slopes (Perry, 1989) and from experience with tips of colliery spoil (McKechnie Thomson \& Rodin, 1972) suggests that these effects are small in fills from British mudstone. However, in any special circumstance in which deep-seated sliding becomes critical, the average operational strength could well be reduced by progressive failure. Probably of greater practical importance is the temporary pollution caused by run-off of acid water from disturbed surfaces of pyritic mudstone.

Dr Cox comments on the collapse of the mudstone fill on wetting. This was observed at the settlement gauges in the downstream fill. Collapse was significant at gauge CS3 in the valley centre. It was just perceptible at gauge AS3 at ch. 400 . The compressions observed after fill placing stopped in 1982 are shown in Fig. 34. Filling at gauge AS3 was predominantly in June and ceased in July; filling at CS3 was placed in August and September. At neither gauge did the fill reach the final slope level in 1982. No control tests were done from which differences in water content could be established, and there was no significant difference in weather conditions as the fills were 


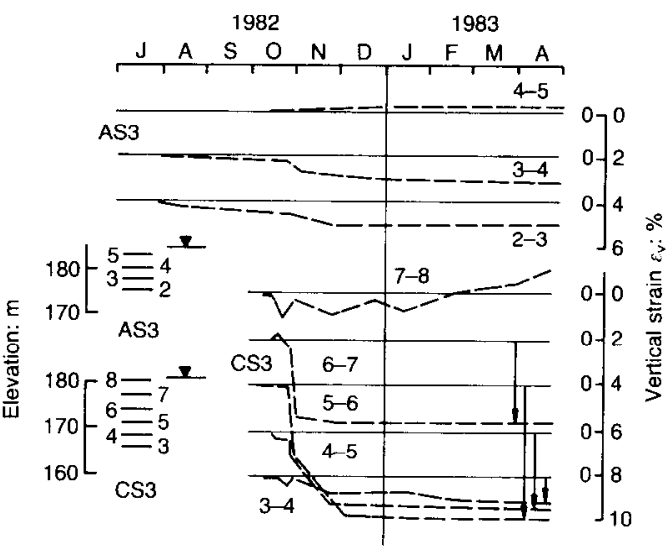

Fig. 34. Settlement and collapse of zone II mudstone fill observed at the two downstream settlement gauges after the 1982 shutdown

placed. However, the borrow pit would have been better developed by August and the fill placed then may have been drier.

An interesting feature of the collapse recorded at gauge CS3 was that it occurred as a wave starting from the top of the fill, taking about two weeks to reach the bottom. Only a small amount of rain could have fallen during such a short period, and thus it seems that the collapse was caused either by a very small inflow of water, or by some other mechanism.

A complicating factor in the Carsington fill is its high pyrite content and its ability to generate sulphuric acid which attacks the carbonate cementation in the mudstone and weakens it. The acid reaction requires both oxygen and water. It is just possible that the fill responds to oxygenation, rather than wetting. However, it is difficult to visualize such a mechanism occurring at both gauges simultaneously, as seems to have happened.

In due course the zone II fill wetted to a considerable extent. Investigation of the downstream fill in 1986 showed an average water content of $17 \%$, compared with $13 \%$ in 1984 , with individual values in excess of $20 \%$. For this reason it was rejected for reuse. The wetting was not consistent in the three boreholes drilled. The increase in water content indicated infiltration of about $1.5 \mathrm{~m}$ of water.

Irrespective of whether the collapse observed was due to the penetration of water or oxygen, it occurred rapidly. It was therefore concluded that any collapse in the upstream fill would have occurred long before the slide developed, and that any effects would have been built out. Collapse of the mudstone fill could only cause second order effects in most of the slide, as the rupture surface did not pass through this fill. Tests performed after the slide showed that the fill was dilatant.

Collapse can occur in heavily compacted fill and, although the fill at Carsington was not heavily compacted, it was placed in thin layers and trafficked by heavy plant, and it could not have been loose. Collapse would make it denscr. Thus liquefaction could not have occurred. The small earthquake shock a few days before the collapse was not felt on site and can have had no significant influence on stability.

Collapse is an interesting phenomenon, and further study of it in relation to the amount of water (or other flux) required to cause it would be useful. However, we do not think it played a significant role in promoting the Carsington slide.

Professor Rowe is right to suggest that data from Carsington will be used to stimulate the development of better analyses, and that there are shortcomings in the finite element analyses as used in the Carsington investigation. However, we think that he underestimates the current success of these methods. The comparisons which he suggests are as follows.

Predictions and observations at the ch. 725 section are compared by Potts et al. (1990). The comparisons at ch. 850, to which Professor Rowe mainly refers, have not been published previously. In both the original Carsington analyses (Babtie Shaw \& Morton \& Skempton, 1986) and the later ones (Dounias, 1987; Potts et al., 1990) the core was modelled in terms of total stress, and no pore pressures were predicted. However, undrained triaxial tests on the Carsington core fill confirmed that pore pressure increased as a function of mean total stress $p$ (Vaughan, Hight,

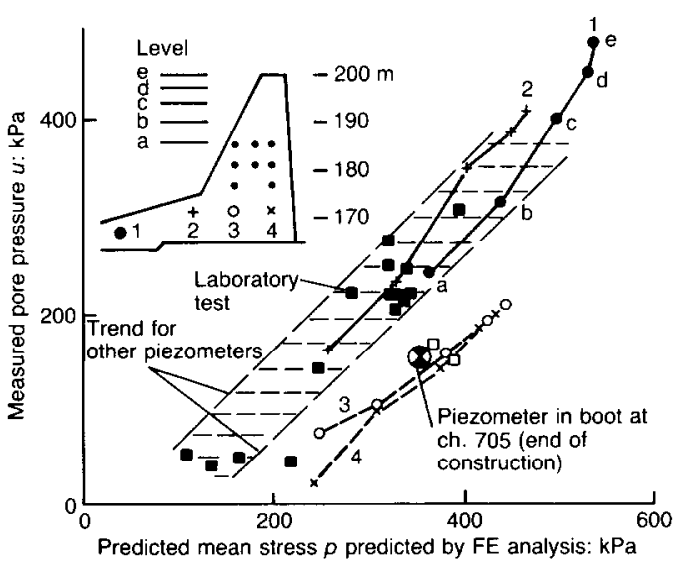

Fig. 35. Pore pressures measured in the core at ch. 850 plotted against mean total stress $p$ predicted by the finite element analysis; laboratory test results are for undrained triaxial tests on undisturbed samples at maximum deviator stress 
Sodha \& Walbancke, 1978). The results from such tests are shown in Fig. 35. Thus it is instructive to plot the pore pressures measured at the piezometers against predicted mean total stress. If pore pressure response is the same, errors in the prediction of total stress should show up as differences in apparent pore pressure response at different piezometers. These plots throw light on arching and load transfer between core and shoulders, and the extent to which this is predicted correctly.

One such plot has been published for ch. 725 (fig. 18 of Potts et al., 1990): a similar plot for ch. 850 is shown in Fig. 35. The pore pressures measured by piezometers 3 and 4 are lower than the general trend, and piezometers 1 and 2 in the boot show rather high pore pressures. This suggests some transfer of load from core to boot not reproduced by the FE analysis. Fig. 18 of Potts et al. (1990) shows a similar general trend for the piezometric readings at $\mathrm{ch}$. 705, except for the one piezometer in the boot. The pore pressure at this piezometer is plotted in Fig. 35. The difference between core and boot shown at ch. 850 is reversed at $\mathrm{ch}$. 705 . The measured pore pressures are more consistent with the loading of fill of different water contents, with local pore pressure redistribution, than with significant load transfer not reproduced by the FE analysis. Differences in pore pressure response are consistent with variations in water content. There was no consolidation in the core and only a small amount in the boot. Since the core was nearly saturated, changes in total stress due to load transfer would

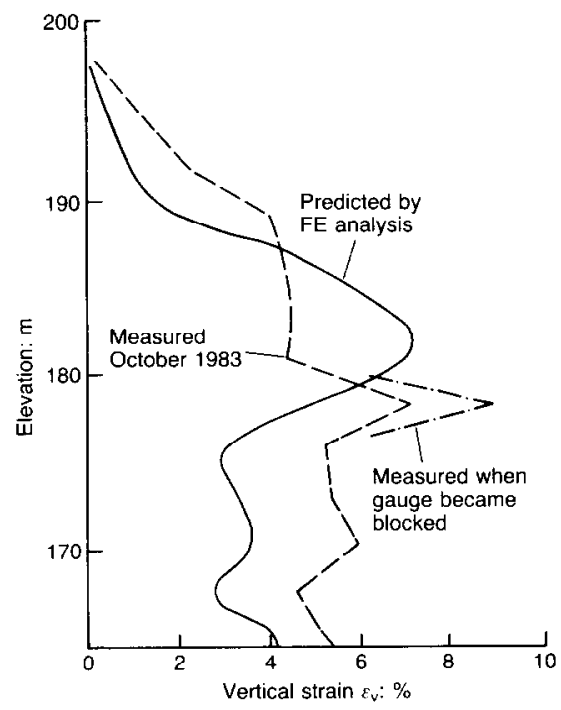

Fig. 36. Measured and predicted vertical strain at the settlement gauge in the core at ch. 850 at the 1983 shutdown have had little influence on strength and hence on stability.

The measured and predicted vertical strains in the core as shown by the settlement gauges are shown for ch. 725 in Fig. 19 of Potts et al. (1990) and for ch. 850 in Fig. 36. The measured settlements in Fig. 36 are those taken shortly before the gauge became blocked. Those plotted by Babtie Shaw \& Morton \& Skempton (1986) are for a slightly earlier date. They do not require correction. In all cases the agreement between measurement and prediction is reasonable. For both sections a high strain zone coincident with the probable rupture surface was both measured and predicted, the measured zone being slightly higher than that predicted at ch. 705 and slightly lower than that at ch. 850. The measured strain is slightly more concentrated at $\mathrm{ch} .850$. The thickness of the zone of concentrated strain predicted is controlled by the size of the clements used in the analysis. Its measured thickness is controlled by the length of the settlement gauge tubes. Its actual thickness may well be less than either.

Vertical displacements at the crest during the winter of 1983-84 were not predicted by the FE analysis, which did not include either consolidation or creep. The overall displacements and strains from core to toe were predicted, but because they were not measured no comparisons can be made. Possible errors due to incorrect modelling of horizontal fill stiffness are discussed by Potts et al. (1990). Non-linear elasticity is used to model pre-failure stiffness and, if observed vertical displacement is matched with this model, horizontal displacement tends to be overestimated. More recently, granular fill has been modelled using the elasto-plastic models due to Lade (Kovacevic, Potts \& Vaughan, 1994). Fig. 37

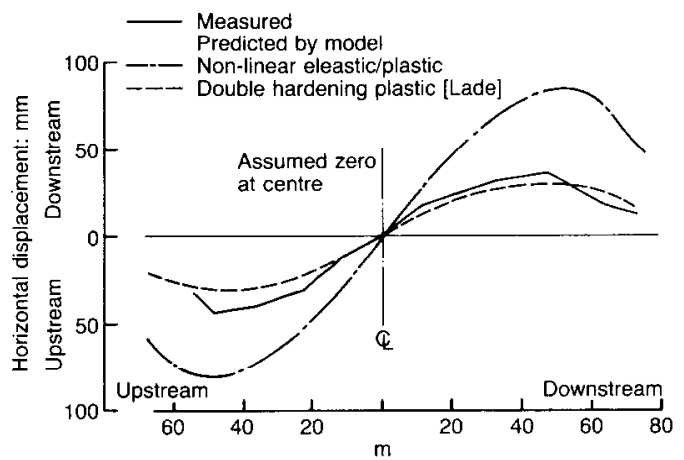

Fig. 37. Horizontal movements measured and predicted in the carboniferous mudstone/sandstone fill of Roadford Dam at the end of construction; the soil models are derived from the same laboratory compression data without adjustment to improve the fit with the field data 
shows the predictions made for lateral movement within the mudstone fill of the Roadford embankment at the end of construction, using the two approaches and those observed (Kovacevic et al., 1994). Both the predictions are based on the same laboratory data, and have not been adjusted to improve the fit. It seems that this difficulty may have been overcome.

The extent to which this computational difficulty affected the prediction of displacement at Carsington is uncertain. The observations started at el. 193, and have been fitted to the predictions at this level (Fig. 11). We do not see how fit could be improved by comparison at a lower level with hypothetical observations deduced by backextrapolation of the actual ones. The rate at which displacement increases with fill height is certainly overpredicted. The measured responses were noticeably stiffer then the predictions after the 1983-84 winter shut-down. Some stiffening would have occurred due to consolidation in the boot during the winter. Time and creep may incrcase stiffness. These effects were not modelled in the analyses.

We are at variance with Professor Rowe over the effects of lateral load transfer. As he points out, a definitive study cannot be made until a full three-dimensional numerical analysis is available. This is still far off. Meanwhile we prefer to use the approximate lumped parameter analysis presented by Babtie Shaw \& Morton \& Skempton (1986) and by Vaughan (1991) to examine this effect, rather than to rely on unsupported hypothesis. We have been unable to recover Professor Rowe's conclusions from this analysis (Babtie Shaw \& Morton \& Skempton, 1986).

An important conclusion from the analysis is that if a length of embankment of about $30 \mathrm{~m}$ reaches a safety factor of less than unity (disturbing force greater than resistance with no net side force operating), then its collapse is inevitable, irrespective of what side force develops. The out-of-balance force which can be generated is sufficient either to form end shears or to drag off the next length of embankment. Thus the initial collapse occurs when a safety factor of unity is reached, without three-dimensional effects, by a mechanism analogous to buckling. Threedimensional effects influence the adjacent sections of the slide. Moreover, the final collapse was abrupt, indicating that, had a factor of safety of unity been reached in 1982, collapse could not have been prevented by the construction of the berm.

It follows that all load transfer effects before June 1984 occurred without any significant length of embankment reaching a factor of safety of unity. All the embankment was in static equilibrium up to this time. In contrast, load transfer after the initial collapse at ch. 720 in June 1984 involved a growing length of embankment which had reached a factor of safety of less than unity, and which was no longer in static equilibrium. Large out of balance forces could then be generated, and the collapse could propagate slice by slice as a ripple effect. This could not happen until after the initial failure. The mechanisms of lateral load transfer before and after the initial collapse are therefore very different from each other.

This dissimilarity can be seen from the field data. Fig. 12 shows the displacements at the toe pegs. The average relative displacement of the sections could be double that shown. At the end of 1983 the relative displacement between pegs at the centre and flank was about $100 \mathrm{~mm}$, with the centre leading. The relative displacement in the opposite direction was more than $600 \mathrm{~mm}$ before the movement at ch. 750 caused movement at ch. 850 in June 1984, and it was more than $1000 \mathrm{~mm}$ before significant movement occurred. Professor Rowe's hypothesis supposes that a relative movement of $100 \mathrm{~mm}$ in one direction will have an effect comparable with that of a relative movement approaching $1000 \mathrm{~mm}$ in the opposite direction.

Professor Rowe postulates that shears in the yellow clay at ch. 725 were formed by load transfer before collapse, and that these weakened this section and so helped induce the collapse. Suppose that the embankment was very stiff, and the small relative movement between the centre and flank at the end of 1983 produced lateral load transfer sufficient to reduce the safety factor on the flank to unity. The force required would be substantial, as the flank was $3.8 \mathrm{~m}$ lower at this time than when it collapsed.

Consider the way in which the shoulder collapses. The FE analysis (Potts et al., 1990) predicts the formation of shears near the boot. Here the clay has been weakened. However, the peak resistance of the whole shoulder is unaffected. The total resistance of the shoulder is reduced only by displacements occurring after its total peak resistance has been reached. Thus the factor of safety must be reduced to unity before overall weakening can occur. It may be argued that loading by lateral load transfer is different from loading by raising the embankment, and that shears formed by the first mechanism could reduce the resistance to the second. However, latcral load transfer would probably impose more uniform displacements, and be less likely to promote local shearing and progressive failure.

If the safety factor were reduced to unity by lateral load transfer, load transfer would be reversed. However, the three-dimensional analysis of load transfer shows that collapse would then 
be inevitable. Its total resistance would be reduced post-collapse, but could not be reduced by pre-collapse movement. In reality, this section collapsed in 1984 when it had been raised substantially and some time after the relative movement of the two sections had been reversed. It could not have behaved in this way if it had reached a factor of safety of unity at the end of 1983. Thus it was never weakened in 1983.

In summary, Professor Rowe and we agree that, once collapse started on the flank, load was transferred to the valley centre, causing the propagation of the collapse across the valley. However, we can find no justification for his hypothesis that prior movement in the valley centre induced the collapse on the flank, nor is such a hypothesis needed to explain the slide. We conclude that between 21 May and 4 June 1984 the embankment was being raised primarily in the vicinity of ch. 725 , which brought it to a state of collapse at this chainage. During 1984 the section at ch. 725 was raised by $3.8 \mathrm{~m}$ (a 14\% increase of core height), and the section at ch. 850 by $2.8 \mathrm{~m}$ (an $8 \%$ increase of core height). At the end of 1983 the height at ch. 725 as a proportion of the height at collapse was significantly lower than at ch. 850. It is unsurprising to us that, with both sections close to collapse, these relatively small changes in the sequence of construction caused ch. 850 to lead during 1983, and ch. 725 to take over in 1984.

The presence of pre-existing shears in the yellow clay is another area of disagreement between Professor Rowe and us. This has been discussed by Skempton, Norbury, Petley \& Spink (1988) and Vaughan \& Chalmers (1992). Their presence could not be determined by direct observations, as they would have been destroyed by the slide. However, they were observed in the yellow clay outside the slide area on similar slopes below and outside the dam, and their presence could be expected from the geology of the area. We believe that it is very probable that they were there, and that, if they were, they reduced the peak strength of the yellow clay. A reduction in this strength, based on the field observations, was made to allow for this in the analyses. The reduction was reduced slightly as the investigation progressed. As a percentage of peak intact strength at the average normal effective stress operating in the yellow clay, the reductions were about 20\% (Skcmpton \& Coats, 1985), 18\% (Skempton, 1985b) and 14\% (Babtie Shaw \& Morton \& Skempton, 1986, and all publications thereafter). Progressive failure reduces the average operational strength of the yellow clay about half way to residual (Potts et al., 1991), and so a reduction in peak strength of $14 \%$ reduces operational strength by about $7 \%$. In Babtie Shaw \&
Morton \& Skempton (1986) the contribution of these shears to the collapse was described as significant, although not major.

$\mathrm{Mr}$ Taylor is wrong to infer that the Authors ever considered that solifluction shears in the yellow clay were the major cause of the slide. Progressive failure was always suspected. Its effect was quantified and thereby fully demonstrated only when the first results of Professor Potts's analyses became available early in 1985 .

The presence of solifluction shears is not necessary to explain the slide, as progressive failure could have a greater effect in compensation. However, we think it much more likely that they were there, and did reduce the strength. We can see no reason for supposing that they were not there.

The divergence in views concerning pre-existing shears in the mudstone fill of the valley centre due to construction methods has been discussed by Vaughan \& Chalmers (1992). Some anisotropy of strength could be expected in this fill, with strength along layers being less than that measured across layers by triaxial tests on in situ samples. The results from the FE analyses combined with the field behaviour support the presence of such an effect, and an allowance has been made for it. In our view there is no direct or indirect evidence that pre-sheared surfaces were caused as the mudstone fill was placed, either due to rutting or due to shear on buried horizontal construction surfaces by compacting plant.

In contrast, Professor Rowe has concluded that extensive horizontal shear surfaces were formed by construction and that they had a major influence on the collapse of this section. He has further concluded that rutting shears should have been formed in the base of the fill, rather than elsewhere, because this fill had been flooded by rising groundwater while it was being placed. The data provided to us from instrumentation of the embankment does not support this view. The pore pressures measured in the foundation did not rise above foundation level until fill placing had started, and the respective rates of rise were then $3 \mathrm{~m}$ per week for the fill and $0.25 \mathrm{~m}$ per week for the water level. It seems unlikely that the contractor would have placed fill in water, and the base drain layer would have taken some time to flood. Water levels did not reach the equilibrium level at el. $170 \mathrm{~m}$ until well into the winter shut-down. No rutting shears were observed in the base of the mudstone fill when the slide was excavated, although they were very evident in the core and boot.

Professor Rowe's comments on water levels were useful to the designers of the new embankment, as they prompted the adoption of foundation de-watering, which enabled the foundation 
to be excavated and the new fill to be placed in the dry (there is no drainage layer on the upstream side) with much less risk of softening and shearing of the foundation or fill by plant. His comments on the formation of shears within the mudstone fill due to construction are also relevant. The designers of the new embankment accepted that this was a risk, and took appropriate measures to produce an embankment which could both tolerate them and from which they were excluded. However, it seems to be a risk which played little part in the collapse of the first embankment.

Professor Rowe's observation that, according to field records, the fill used in the base of the valley may have been more clayey than elsewhere is interesting. It could not have had a lower strength than the zone I fill, which the design shows should have been used close to the boot. The peak strength would then bc reduced to the lower bound quoted in Table 6. The effect on the conclusions drawn in the Paper would be small.

Professor Rowe points to an apparent inconsistency between the text and Fig. 17. The text refers to the bottom of the valley where no yellow clay was present between ch. 970 and ch. 1040. This refers to the bottom of the valley of the tributary stream shown in Fig. 17; it does not refer to the whole of the foundation between ch. 970 and ch. 1040. The drawing is correct.

Professor Rowe has misread the Paper concerning the small area of shearing in the foundation below the south end of the slide shown in Fig. 17. The shear was on bedding planes in the weathered mudstone below the yellow clay, on which the strength was insufficient to resist the stress imposed by the embankment. Had they not been disturbed in general by periglacial cryoturbation, such bedding planes could have presented a stability hazard (Vaughan, Johnston \& Chalmers, 1991).

The critical attention Professor Rowe has paid to the Carsington slide and to the Paper has stimulated full exploration of alternative mechanisms, both during and after the investigations, by all those concerned. This exploration has confirmed for us that the conclusions drawn from the investigation and presented in the Paper are the probable explanation of the slide, and are consistent with the known facts.

\section{CORRIGENDA}

In the second column of Table 6 the value for zone II fill $\Phi^{\prime}$ should read $25^{\circ}$, not $24^{\circ}$.

In the right-hand column of text 201 in line 7 should rcad 202 and 202 in line 15 should read 203.

\section{REFERENCES}

Akiba M. Sembatt (1941). The earthquake and its influence on reservoirs in Akita prefecture. J. Agric. Engng Soc. Japan 13, No. 1.

Babtie Shaw \& Morton \& Skempton, A. W. (1984). Carsington Dam: investigation of embankment. Interim report to Severn Trent Water Authority.

Babtit Shaw \& Morton \& Skempton, A. W. (1985). Carsington Dam: the mechanism of failure. Report on principal findings.

Babtie Shaw \& Morton \& Skempton, A. W. (1986). Carsington Dam: investigation of embankment. The mechanism of failure. Report to Severn Trent Water Authority, vol. 1.

Binnie, G. M. (1978). The collapse of Dale Dyke dam in retrospect. $Q . J$. Engng Geol. 11, 305-324.

Bjerrum, L. (1960). Some notes on Terzaghi's method of working. From theory to practice in soil mechanics. New York and London: Wiley.

Chalmers, R. W., Vaughan, P. R. \& Coats, D. J. (1993). Reconstructed Carsington Dam: design and performance. Proc. Instn Civ. Engrs Wat. Marit. \& Energy 101, Mar., 1-16; Discussion 112, Dec.

Chen, Z., Morgenstern, N. R. \& Chan, D. H. (1992). Progressive failure of the Carsington Dam: a numerical study. Can. Geotech. J. 29, 971-988.

Cox, D. W. (1979). Volume change in compacted clay fill. In Clay fills, pp. 79-86. London: Institution of Civil Engineers.

Coxon, R. E. (1984). Failure of Carsington embankment. Interim report to the Secretary of State for the Environment. London: Department of the Environment.

Coxon, R. E. (1986). Failure of Carsington Embankment. Report to Secretary of State for the Environment. London: Department of the Environment.

Dounias, G. T. (1987). Progressive failure in embankment dams. PhD thesis, University of London.

Dounias, G. T., Potts, D. M. \& Vaughan, P. R. (1989). Numerical stress analysis of progressive failure and cracking in embankment dams. Report to the Department of the Environment, Contract PECD 7/7/222. Garston: Building Research Establishment.

Gilbertson, A. L. \& Rowe, P. W. (1988). Silo interactions. British Sugar plc Technical Conference, Eastbourne.

Gu, W. H., Morgenstern, N. R. \& Robertson, P. K. (1993). Progressive failure of Lower San Fernando Dam. J. Geotech. Engng Div. Am. Soc. Civ. Engrs 119, No. 2, 333-349.

Institution of Civil Engineers, Association of Consulting Engineers \& Federation of Civil Engineering Contractors (1973). Conditions of contract and forms of tender, agreement and bond for use in conjunction with works of civil engineering construction, 5th edn. London: ICE, ACE and FCEC.

Kennard, M. F. (1983). Report on consideration of embankment stability by Rofe Kennard \& Lapworth to Shephard Hill Ltd. November 1983.

Kovacevic, N. (1994). Finite element analysis of embankment dams. PhD thesis, University of London. In preparation.

Kovacevic, N., Potts, D. M. \& Vaughan, P. R. (1994). Finite element analysis of a rockfill dam. Session 19B. Proc. 8th Int. Conf. Computer Meth. Adv. Geomech., Morgantown 3, 2459-2464. 
Ladd, C. C. (1991). Stability evaluation during staged construction. J. Geotech. Engng Am. Soc. Civ. Engrs 117, No. 4, 538-615.

Macdonald, A., Dawson, G. M. \& Coleshill, D. C. (1993). Reconstructed Carsington Dam: construction. Proc. Instn Civ. Engrs Wat. Marit. \& Energy 101, Mar., 17-30; Discussion 112, Dec.

McKechnie Thomson, G. \& Rodin, S. (1972). Colliery spoil tips after Aberfan. London: Institution of Civil Engineers.

Naylor, D. J. (1989). Discussion on Carsington Dam. In Clay barriers for embankment dams, pp. 169-171. London: Thomas Telford.

Parsons, A. W. \& Perry, J. (1985). Slope stability problems in ageing highway earthworks. In Failures in earthworks, pp. 63-78. London: Thomas Telford.

Penman, A. D. M. (1986). On the embankment dam. Géotechnique 36, Sept., 301-348.

Penman, A. D. M. (1992). Discussion on A reassessment of the causes of the Carsington embankment failure, by P. W. Rowe. Géotechnique 42, Sept., 513-514.

Perry, J. (1989). A survey of slope condition on motorway earthworks in England and Wales. Research report 199. Crowthorne: Transport \& Road Research Laboratory.

Potts, D. M., Dounias, G. T. \& Vaughan, P. R. (1990). Finite element analysis of progressive failure of Carsington embankment. Géotechnique 40, Mar., 79101.

Potts, D. W., Kovacevic, N. \& Vaughan, P. R. (1994). The design of slopes for highway cuttings and embankments. Contract report 5530. Crowthorne: Transport Research Laboratory. In Draft.

Rowe, P. W. (1986). The potentially latent dominance of ground water in ground engineering. In Groundwater in engineering geology, pp. 27-42. London: Geological Society.

Rowe, P. W. (1991). A reassessment of the Carsington embankment failure. Géotechnique 41, No. 3, 395422.

Rowe, P. W. (1992). Reply to discussion on A reassessment of the Carsington embankment failure. Géotechnique 42, Sept., 521-524.

Seed, H. B. (1979). Considerations in the earthquake resistant design of earth and rockfill dams. Géotechrique 29, Sept., 215-263.

Skempton, A. W. (1985a). Residual strength of clays in landslides, folded strata and the laboratory. Géotechnique 35, Mar., 3-18.

Skempton, A. W. (1985b). Geotechnical aspects of the Carsington Dam failure. Proc. 11th Int. Conf. Soil Mech., San Francisco 5, 2581-2591.

Skempton, A. W. \& Coats, D. J. (1985). Carsington Dam failure. In Failure in earthworks, pp. 203-220. London: Thomas Telford

Skempton, A. W., Norbury, D., Petley, D. J. \& Spink, T. W. (1989). Solifluction shears at Carsington, Derbyshire. Proc. 25th An. Conf. Engng Gp, Geol. Soc. Lond., 277-285.
Skempton, A. W. \& Vaughan, P. R. (1989). Discussion on Carsington Dam. In Clay barriers for embankment dams, pp. 182-186. London: Thomas Telford.

Vaughan, P. R. (1991). Stability analysis of deep slides in brittle soil-lessons from Carsington. In Slope stability engineering, pp. 1-11. London: Thomas Telford.

Vaughan, P. R. \& Chalmers, R. W. (1992). Discussion on $A$ reassessment of the Carsington embankment failure, by P. W. Rowe. Géotechnique 41, No. 3, 395422.

Vaughan, P. R., Hight, D. W, Sodha, V. G. \& Walbancke, H. J. (1978). Factors controlling the stability of clay fills in Britain. In Clay fills, pp. 205-218. London: Thomas Telford.

Vaughan, P. R., Johnston, T. A. \& Chalmers, R. W. (1991). Foundation conditions at the reconstructed Carsington Daml. Trans. I7th Int. Congr. Large Dams, Vienna, Q. 66, 1539-1554.

Vaughan, P. R. (1993). Engineering behaviour of weak rocks: some answers and some questions. Geotechnical engineering: hard soils--soft rocks, vol. 3, Athens: Balkema. To be published.

\section{BIBLIOGRAPHY}

Anderson, W. F. \& Cripps, J. C. (1990). The effects of acid leaching on the shear strength of Namurian shale. In Engineering geology of weak rocks (eds J. C. Cripps et al.), pp. 159-168. Rolterdam : Balkema.

Davey, P. G. \& Eccles P. G. (1983). The Carsington scheme-reservoir and aqueduct. Proc. Inst. Wat. Enars Scientists 37, 215-239.

Dounias, G. T., Potts, D. M. \& Vaughan, P. R. (1988). Finite element analysis of progressive failure: two case studies. Computs Geotechnics 6, 155-175.

Macdonald, A. \& Reid, J. M. (1990). Embankment dam behaviour: the contribution of geochemistry. In The embankment dam, pp. 163-169. London: Thomas Telford.

Reid, J. M. \& Chalmers, R. W. (1990). Permeability testing of weak fissured rock at Carsington Dam. In Engineering geology of weak rocks (eds J. C. Cripps et al.), pp. 273-282. Rotterdam: Balkema.

Ross, K. A. (1992). Design and construction of the core filter for Carsington Dam. Dams \& Reservoirs, 19-23.

Vaughan, P. R. (1985). Rotura de una presa de tierra instrumentada (Failure of an instrumented embankment dam). In Instrumentacion de Obras, pp. 419450. Barcelona: Universitat Polytechnica de Catalunya.

Vaughan, P. R., Dounias, G. T. \& Potts, D. M. (1989). Advances in analytical techniques and the influence of core geometry on behaviour. In Clay barriers for embankment dams, pp. 87-108, 175-180. London: Thomas Telford. 